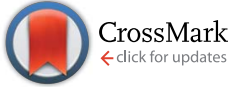

Cite this: RSC Adv., 2017, 7, 919

Received 1st November 2016 Accepted 25th November 2016

DOI: 10.1039/c6ra26157d

www.rsc.org/advances

\section{Spectroscopic markers for uranium(vi) phosphates. Part II: the use of time-resolved photoluminescence}

\begin{abstract}
F. Massuyeau, ${ }^{a}$ D. L. Perry, ${ }^{b}$ N. Kalashnyk ${ }^{c}$ and E. Faulques ${ }^{\star a}$
Detection of uranium hydrates that are relevant for environmental sustainability and adsorption at surfaces is effected using time-resolved photoluminescence spectroscopy (TRPL) with simultaneous lifetime and spectral acquisitions. The study is the second paper devoted to this topic (part I: Faulques et al. RSC Adv., $2015,5,71219)$ and focuses on photoluminescence (PL) phenomena. When a temporal dimension is added, the TRPL technique surpasses, via PL decay analysis, steady-state approaches for discriminating minerals with very similar optical and PL spectra. Further, estimates of quantum yields and nonradiative lifetimes can be given. The results are pertinent in the context of remote sensing of parent hazardous uranyl compounds in the environment.
\end{abstract}

\section{Introduction}

The study of uranium in natural systems has drawn much attention, primarily due to its strong significance to geological and oceanographic chemistry as well as for environmental sustainability. This element is naturally radioactive and highly toxic. Uranium phase recognition becomes, therefore, extremely challenging for potential environmental risks and investigations of uranium(vi) mobility that depends on its adsorption at surfaces. The detection of uranium in soils, waters, and living bodies can be performed directly by different optical spectroscopy techniques, including, in particular, luminescence spectroscopy.

The first studies probing uranyl luminescence date back more than a century ago when earlier optical experiments were intimately associated with the discovery of radioactivity. Later, it has been established that this luminescence is very sensitive to the coordination chemistry of the uranyl ion. ${ }^{1-5}$ The main historical facts of uranyl luminescence research have been summarized by Formosinho et al. ${ }^{6}$ while the electronic and vibrational properties of actinyl ions (including uranyl) were thoroughly reviewed by Denning. ${ }^{7}$

Steady-state photoluminescence (PL) of natural and synthetic uranyl phosphates and carbonates is well documented for solids and solutions in a number of studies. ${ }^{8-17}$

${ }^{a}$ Institut des Matériaux Jean Rouxel (IMN), Université de Nantes, CNRS, 2 rue de la Houssinière, BP 32229, 44322 Nantes Cedex 3, France. E-mail: eric.faulques@ cnrs-imn.fr

${ }^{b}$ Lawrence Berkeley National Laboratory, University of California, Mail Stop 70A-1150, Berkeley, CA 94720, USA

'Institut Jean Lamour (IJL), Université de Lorraine, CNRS, UMR 7198, Parc de Saurupt, CS 50840, 54011 Nancy, France
Various investigations of uranyl ion luminescence quenching by water and time-resolved photoluminescence spectroscopy (TRPL) experiments on uranyl crystals and phosphates in solid state or in solutions have been previously published..$^{\mathbf{1 0 1 3 , 1 8 - 3 1}}$ The advantages of the TRPL technique over stationary photoluminescence are the following: an intense laser beam with a focused spot impinges onto the sample, allowing the detection of very weak PL signals on low material amounts; PL spectra can be recorded not only in the energy domain but also in the time domain, therefore, permitting physical analysis of PL mechanisms. In particular, PL lifetimes are sensitive to structural and environmental changes of the emitting species, to carrier trapping, and to dynamical processes like carrier/exciton recombination or diffusion. This technique permits also the estimation of deactivation rate constants in the excited state.

The minerals investigated in the present work are several uranyl hydrated phosphates, including alkaline earth uranyl phosphates: saleeite $\mathrm{Mg}\left(\mathrm{UO}_{2}\right)_{2}\left(\mathrm{PO}_{4}\right)_{2} \cdot 10 \mathrm{H}_{2} \mathrm{O}$, metatorbernite $\mathrm{Cu}\left(\mathrm{UO}_{2}\right)_{2}\left(\mathrm{PO}_{4}\right)_{2} \cdot 8 \mathrm{H}_{2} \mathrm{O}$, uranocircite $\mathrm{Ba}\left(\mathrm{UO}_{2}\right)_{2}\left(\mathrm{PO}_{4}\right)_{2} \cdot 10 \mathrm{H}_{2} \mathrm{O}$, ulrichite $\mathrm{CaCu}\left(\mathrm{UO}_{2}\right) \quad\left(\mathrm{PO}_{4}\right)_{2} \cdot 4 \mathrm{H}_{2} \mathrm{O}$, and phosphuranylite $\mathrm{KCa}\left(\mathrm{H}_{3} \mathrm{O}\right)_{3}\left(\mathrm{UO}_{2}\right)_{7}\left(\mathrm{PO}_{4}\right)_{4} \mathrm{O}_{4} \cdot 8 \mathrm{H}_{2} \mathrm{O}$. These minerals consist of a coordination core of hexavalent uranium surrounded by water molecules and the oxygen atoms both donated by the anionic phosphate functional group and those associated with the uranium. Their corresponding detailed crystal structures can be found in the literature. ${ }^{32-36}$

The aim of the present work is to revisit previously published data on these minerals, and to provide a new record on the detection of uranyl moieties following a recent study by the same authors using steady-state PL, optical absorption, Raman and infrared spectroscopy. ${ }^{17}$ Here, simultaneous temporal and spectral data acquisition is performed with a yet unemployed 

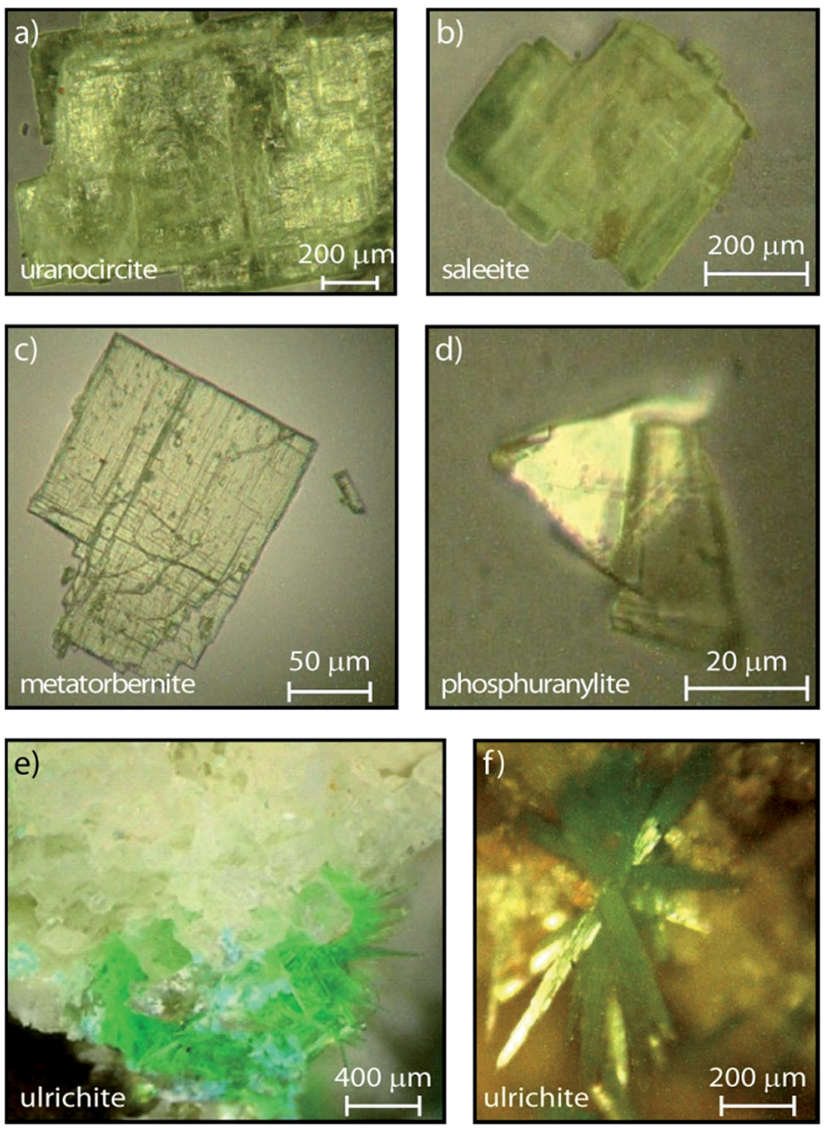

Fig. 1 Microphotographs of crystallites investigated in this study and in: ${ }^{17}$ (a) uranocircite, (b) saleeite, (c) metatorbernite, (d) phosphuranylite, (e) ulrichite spot on rock at low magnification, (f) ulrichite at higher magnification showing the radiating crystals $(\sim 400 \mu \mathrm{m} \times 40$ $\mu \mathrm{m})$.

TRPL technique based on multichannel detection provided by streak camera equipment. In short, this method allows simultaneous recording of many PL transients at the same span of time, the number of time channels being equal to the number of pixels in the vertical direction of the CCD employed for the signal detection.

Luminescence quantum yields and lifetimes, mostly unknown before, are now estimated via the decay analysis of the minerals. Several of these hydrated compounds exhibit quenching of luminescence explained in terms of the crystalline environment of the materials. These findings might have importance not only for fundamental studies but also for the field of uranium environmental research and tracking. The latter aspect is motivated by early recognition of TRPL as a potential remote-sensing technique for selective uranium detection in uranyl geological targets. ${ }^{37}$

\section{Experimental}

\subsection{Instrumentation}

TRPL experiments were carried out with a regenerative amplified femtosecond Ti:Sapphire laser system (Spectra Physics
Hurricane $\mathrm{X}$ ) producing $100 \mathrm{fs}$ pulses at $800 \mathrm{~nm}$ with a repetitive rate of $1 \mathrm{kHz}$. The laser line is frequency doubled in a second harmonic generator to give the excitation wavelength $\lambda_{\mathrm{exc}}=$ $400 \mathrm{~nm}(3.1 \mathrm{eV})$. The femtosecond laser pulse traces were controlled by an oscilloscope WavePro 950 Lecroy operating with an analog bandwidth of $1 \mathrm{GHz}$. The emission spectra were temporarily resolved using a high dynamic range Hamamatsu C7700 streak camera of temporal resolution $<20$ ps equipped with (i) a $7 \mathrm{~mm} \times 17 \mathrm{~mm}$ S20 photocathode designed for detecting signals between 200 and $850 \mathrm{~nm}$; (ii) an image intensifier of $25 \mathrm{~mm}$ diameter with a $\mathrm{P} 43$ phosphor screen and a removable fiber coupling entrance on the streak tube; (iii) an achromatic entrance optical lens with $f / 3.5$ aperture with adjustable focus; (iv) an exit optical lens at magnification $2: 1$ and f/2.5 with adjustable focus; (v) a readout CCD ORCAII camera Peltier cooled to $-60{ }^{\circ} \mathrm{C}$ with a $1344 \times 1024$ pixels resolution, 12 bit sampling and pixel size $6.45 \times 6.45 \mu \mathrm{m}$. The 1344 and 1024 pixels record the spectrum and the sweep time, respectively. The laser beam is filtered in a Pellin-Broca prism and sent through density filters. It is focused onto the sample by a UV grade fused silica bi-convex lens. The excitation density in the sample was adjusted with density filters to avoid sample photodegradation. The fluorescence was collected by a spherical mirror (UV enhanced aluminum, diameter $76.2 \mathrm{~mm}$, focal length $152.4 \mathrm{~mm}$, aperture $f / 2$ ), and focused onto the spectrograph slit by a second planar UV enhanced and protected aluminum mirror. EKSPLA or Newport bandpass colored glass filters were placed in front of the spectrograph entrance to remove the reflected laser beam.

The transient signals were spectrally dispersed into a Princeton Instruments SP2300 imaging Acton spectrograph specially fitted for the streak camera (focal length $300 \mathrm{~mm}$, aperture ratio $f / 3.9$, gratings with $150 \mathrm{~g} \mathrm{~mm}^{-1}$, blazed at 500 $\mathrm{nm}$ ) with a slit opening of $25 \mu \mathrm{m}$. The streak camera sweep was triggered by the laser pulses via an internal (0-100 ns) SpectraPhysics synchronous delay generator, (SDG II) and an external delay generator (from $100 \mathrm{~ns}$ to $1 \mathrm{~ms}$ ) Stanford Research Systems plugged onto the laser. The spot size of the laser beam impinging onto samples was about $300 \mu \mathrm{m}$, with typical laser powers between $0.9 \mathrm{~mW}$ and $44 \mathrm{~mW}$. Transient fluorescence images were acquired with analog integration methods, and no sample degradation was observed.

\subsection{Materials and methods}

The certified minerals were obtained from Mineralogical Research Company (Minresco, San Jose, CA, USA). Geographical origins of the studied minerals are given in our previous work, ${ }^{17}$ while the microphotographs of the crystallites are shown in Fig. 1.

Experiments were conducted in the solid-state at room temperature (RT). Small crystallites (phosphuranylite, uranocircite), or crystalline platelets (metatorbernite, saleeite), were deposited onto fused silica plates. Alternately, approximately 1 $\mathrm{mm}^{3}$ of tiny acicular ulrichite crystals radiating from the matrix of a rock fragment were studied as provided using a gemological, movable sample holder. The streak camera enables direct 
lifetime measurements of the transient PL. Streak image backgrounds are removed in all experiments after acquisition. Calibration of the spectrograph was made by recording several intense laser lines at $400 \mathrm{~nm}$ along the horizontal direction of the CCD and checking that the position and intensity of this line were unchanged. The temporal and spectral PL profiles were reproduced using appropriate kinetics-decay analysis and Voigt spectral shape modeling, respectively. All spectral fits to the experimental data were performed by minimizing $\chi^{2}$ or maximizing the coefficient of correlation $R^{2}$ with the free software Fityk 0.9.8 by Marcin Wojdyr under GNU General Public License. The PL spectra were fitted using Voigt functions with a Levenberg-Marquardt iteration algorithm. Time-resolved data were acquired and analyzed with the HPD-TA software provided with the streak camera. For each sweep time, the fluorescence image was averaged by sampling 3 to 10 exposures over different exposure times depending on the CCD signal. The fluorescence dynamics (growth and decay) were subsequently treated with commercial data software and reproduced using the model described in the text. An apparatus function was included in the temporal fits. The fits were applied to the spectra expressed in energy units to reproduce the vibronic spectral components with more accuracy.

\section{Results and discussion}

The streak camera images consist of three-dimensional (3D) data sets providing the photoluminescence intensity $v s$. emission wavelength and $v s$. time delay (ns to $\mu \mathrm{s}$ ) after excitation. Therefore, the novelty of the present study in comparison with our previous work $\mathrm{k}^{\mathbf{1 7}}$ lies in the PL lifetime study of these uranyl phosphates. The PL images of the samples are recorded in the 344-706 nm spectral range (1.76-3.60 eV) allowed by the grating and covering the full rectangular CCD surface (Fig. 2). Some samples have a globally similar spectral character but clearly present various delayed luminescence appearing in either the 2 $\mathrm{ns}, 50 \mathrm{~ns}, 20 \mu \mathrm{s}, 200 \mu \mathrm{s}$, or $500 \mu \mathrm{s}$ time windows.

Kinetics were modeled including the temporal dependence of the laser pulse with contribution of a Gaussian apparatus function. The best reproduction of the kinetics was achieved by analytical integration of the following differential equations for exponential decays in a multi-level approach comprising the electronic ground state and one or two independent excited states

$$
\frac{\mathrm{d} n_{i}}{\mathrm{~d} t}=G(t)-k_{i} n_{i}
$$

where $G(t)$ is the Gaussian exciton generation function, $n_{i}$ is the total population of photogenerated moieties in the excited energy states $i=1$ and 2 with initial condition $n_{i}(-\infty)=0$, and $k_{i}$ $=\tau_{i}^{-1}$ is the inverse of decay lifetime (i.e. the rate constant). As a support of this model, (i) a bi-exponential behavior of the decay kinetics was also found by Lopez and Birch in aqueous uranyl solutions, ${ }^{38}$ and by Baumann et al. ${ }^{19}$ in the minerals autunite, metaautunite, and chernikovite, (ii) our attempts to reproduce the decays with Kohlrausch stretched exponentials were unsuccessful and highly inaccurate for global images and for
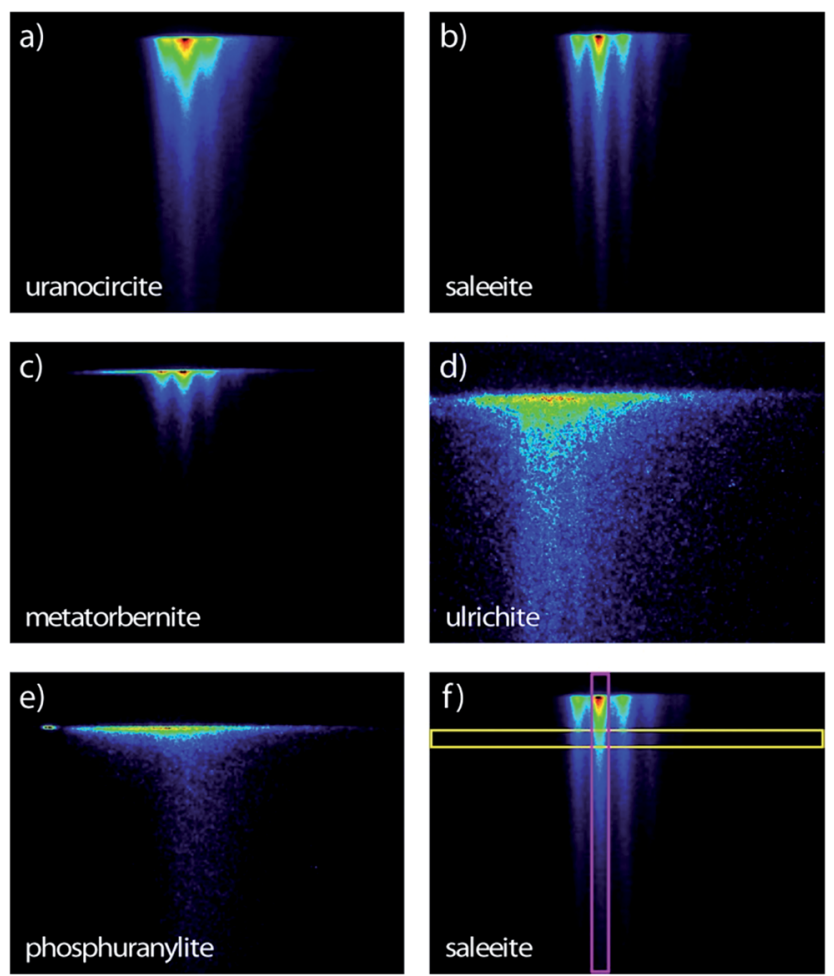

Fig. 2 Streak camera images contours of the room temperature timeresolved $\mathrm{PL}$ with sweep ranges indicated in parentheses of (a) uranocircite $(20 \mu \mathrm{s}),(b)$ saleeite $(500 \mu \mathrm{s}),(c)$ metatorbernite $(200 \mu \mathrm{s})$, (d) ulrichite ( $2 \mathrm{~ns}$ ) and (e) phosphuranylite (50 ns). The time extends on the vertical direction. (f) Thin vertical (pink) and horizontal (yellow) regions of interest explaining Fig. 5 and 6, respectively. Spectral window: (a-c, e) 366-729 nm; (d) 407-768 nm. Excitation: $400 \mathrm{~nm}$. The PL intensity increases from blue color to red color.

individual wavelengths centered on regions of interest (ROIs) of $5 \mathrm{~nm}$. A significant bi-exponential decay can be explained by the presence of at least two different lattice sites of $\mathrm{U}(\mathrm{vI})$ with different water coordination in the studied minerals. ${ }^{19}$

We note that the $n_{i}$ populations include species recombining radiatively and nonradiatively onto the ground state, which is supposed to be negligibly depopulated at RT. In this case, the observed temporal signal (growth and decay) is

$$
S(t)=\sum_{i=1}^{2} A_{i} n_{i}(t)
$$

where the $A_{i}$ are proportional to the PL intensity from levels $i$. The analytical function $S(t)$ does not involve simple exponentials, but a combination of exponentials with error function $\operatorname{erf}(t)$. The fitting procedure includes the removal of remaining background, which might be still present in spectra after dark images subtraction.

The time-resolved PL of the minerals at RT is made up of intense emissions comparatively close in energy as shown in Fig. 3. The origin of these PL emissions in the green spectrum can be ascribed to electronic transitions between the nonbonding U-5f $\delta_{\mathrm{u}}$ and $\varphi_{\mathrm{u}}$ LUMOs and the $\mathrm{U}(5 \mathrm{f})-\mathrm{O}(2 \mathrm{p})$ bonding $\sigma_{\mathrm{u}}$ HOMO of the uranyl ion..$^{39,40}$ 


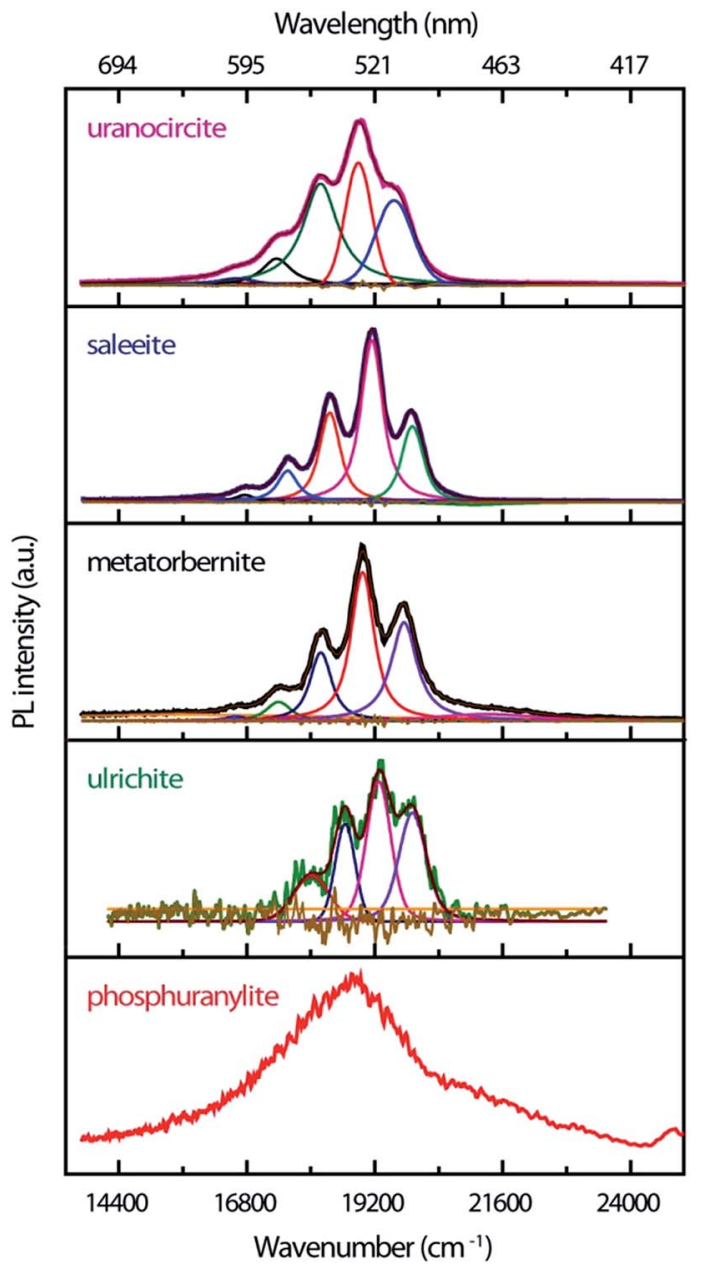

Fig. 3 Time-resolved luminescence spectra of uranyl-containing minerals temporally integrated on the following sweep time ranges from top to bottom: $20 \mu \mathrm{s}, 500 \mu \mathrm{s}, 200 \mu \mathrm{s}, 2 \mathrm{~ns}, 50 \mathrm{~ns}$. The vibronic bands are decomposed in Voigt shapes. The spectrum of ulrichite has been upgraded by removal of a strong fluorescence background. The spectrum of phosphuranylite cannot be resolved and no further spectral treatment was done. The original wavelength scale used by the instrument is given for guide with tick label values unequally spaced.

The PL bands show strong coupling of lattice phonons with the electronic transitions. The spacing between the most intense vibronic peaks of about $800-850 \mathrm{~cm}^{-1}$ is due to the O-U-O symmetric $\nu_{1}$ phonon stretching mode which is Ramanactive. The spectra are of good quality, especially for those samples available in very low amounts (ulrichite, phosphuranylite). The non-smoothed ulrichite spectrum is background removed with a broad Gaussian profile of $5621 \mathrm{~cm}^{-1}$ width. While steady state experiments evidence hot PL bands, ${ }^{\mathbf{1 7}}$ these weak features are not definitely identified in the present transient spectra. Their possible contributions might be shifted with larger intensity or merged in the fluorescence background. Table 1 compiles the TRPL emission energies found by fitting the PL bands with Voigt functions in the current study.

The vibronic component maxima and the FWHM of the fitted peaks are presented in $\mathrm{cm}^{-1}$ units with uncertainty linked to fitting accuracy. The smallest intervals around $700 \mathrm{~cm}^{-1}$ could correspond to the energy separations associated with the $\mathrm{O}-\mathrm{U}-\mathrm{O}$ symmetric stretching phonon of the lowest excited state as can be seen from absorption experiments, ${ }^{17,40}$ although the corresponding bands are much higher in intensity than in a steady state. The largest interval values above $754 \mathrm{~cm}^{-1}$ correspond within wavenumber uncertainty to the vibrational Raman-active frequency of uranyl moieties in the ground state, and they are close to those determined earlier in our steady state experiments. ${ }^{17}$

Saleeite and uranocircite show PL spectra centered around $19119 \mathrm{~cm}^{-1}$ and $18889 \mathrm{~cm}^{-1}$, respectively. The spectra are relatively well structured and resolved with strong relative intensity differences in the components of the vibronic structure. Metatorbernite is a mineral with PL transients close both to saleeite in relative intensities and to uranocircite in spectral locations, but with different PL kinetics. The metatorbernite peaks are slightly redshifted with respect to saleeite, with a maximum PL around $18967 \mathrm{~cm}^{-1}$.

The emission of phosphuranylite (Fig. 3) is non-structured with a large band centered around $18835 \mathrm{~cm}^{-1}$. It is possible to distinguish a shoulder at about $21276 \mathrm{~cm}^{-1}$. The broad spectrum of this mineral is ascribed to the many vibrational modes arising from three different uranyl sites in the crystal and is almost identical to steady-state PL spectra recorded elsewhere. ${ }^{\mathbf{4 1}-43}$ Ulrichite also presents a broad PL band with weak intensity due to the low amount of material. The PL maximum is located around $19251 \mathrm{~cm}^{-1}$ with a vibronic structure better resolved after spectral background treatment.

Fig. 4 displays the temporal profiles taken by integrating the PL intensity over the whole spectrum. All minerals present a more or less pronounced bi-exponential non-linear PL decay in semi-log scales as observed in other studies. ${ }^{\mathbf{1 9 , 4 3}}$ In fact, uranocircite and saleeite luminescence can be ascribed to mainly one uranyl species. The other minerals exhibit a more nonlinear decay which can be attributed to at least two different uranyl species yielding short-lived and long-lived luminescence.

In Table 2, the decay times of the PL have been reported and compiled. $R^{2}$ of the fits is $>0.99$ except for ulrichite. From Fig. 4 and Table 2, saleeite has the longest lifetime among the investigated minerals, and its decay is almost mono-exponential with a PL extending up to $500 \mu \mathrm{s}$ and a decay time $\tau_{2}$ of $153 \mu \mathrm{s}$. This value is comparable to the lifetime $\tau_{2}$ found by Othmane et al. ${ }^{20}$ in autunite. In contrast, the lifetime of uranocircite is about twenty times shorter $(7 \mu \mathrm{s})$ with a quasi-linear PL decay. The PL of metatorbernite is decaying with a bi-exponential function and yields a $\tau_{2}$ lifetime of $32 \mu$ s closer to that of uranocircite. The lifetimes of the bi-exponential PL decays in ulrichite and phosphuranylite are in the nanoseconds range with $\tau_{2}$ values of 1.1 and $9.1 \mathrm{~ns}$, respectively.

Fig. 5 presents the temporal evolution of the strong vibronic bands in three minerals. In the case of saleeite and metatorbernite, the luminescence decay curves in ROIs (all colored curves except the red ones in Fig. 5) are limited to the most intense individual vibronic components (thin vertical pink ROIs like in Fig. 2). They are hardly distinguishable from the whole spectrally integrated ones (red curves in Fig. 5). The luminescence is decaying at essentially the same rate in each mineral for 
Table 1 TRPL energies excited at $400 \mathrm{~nm}$, vibronic separations and FWHM of the studied minerals obtained by fits to the spectra with Voigt functions $^{a, b}$

\begin{tabular}{|c|c|c|c|}
\hline \multirow[b]{2}{*}{ Minerals } & TRPL peaks $\left(\mathrm{cm}^{-1}\right)$ & \multirow[b]{2}{*}{ FWHM $\left(\mathrm{cm}^{-1}\right)$} & \multirow[b]{2}{*}{$R^{2}$} \\
\hline & Vibronic separations & & \\
\hline Uranocircite $\mathrm{Ba}\left(\mathrm{UO}_{2}\right)_{2}\left(\mathrm{PO}_{4}\right)_{2} \cdot 10 \mathrm{H}_{2} \mathrm{O}$ & $\begin{array}{l}16594 \mathrm{w}( \pm 62)-17348( \pm 25)-18169( \pm 6) \\
-18877( \pm 5)-19544( \pm 12) \\
754( \pm 37)-821( \pm 19)-708( \pm 1)-667( \pm 7)\end{array}$ & $\begin{array}{l}386( \pm 100)-653( \pm 7)-790( \pm 60) \\
-585( \pm 10)-815( \pm 103)\end{array}$ & 0.9997 \\
\hline Ulrichite $\mathrm{CaCu}\left(\mathrm{UO}_{2}\right)\left(\mathrm{PO}_{4}\right)_{2} \cdot 4 \mathrm{H}_{2} \mathrm{O}$ & $\begin{array}{l}17730( \pm 30)-18510( \pm 57)-19290( \pm 8) \\
-20080( \pm 30) \\
780( \pm 27)-780( \pm 49)-790( \pm 22)\end{array}$ & $\begin{array}{l}943( \pm 200)-538( \pm 19)-678( \pm 53) \\
-763( \pm 163)\end{array}$ & $\begin{array}{l}0.9430 \\
\text { (noisy spectrum) }\end{array}$ \\
\hline Metatorbernite $\mathrm{Cu}\left(\mathrm{UO}_{2}\right)_{2}\left(\mathrm{PO}_{4}\right)_{2} \cdot 8 \mathrm{H}_{2} \mathrm{O}$ & $\begin{array}{l}16594 \mathrm{w}-17388( \pm 33)-18182( \pm 11) \\
-18965( \pm 8)-19744( \pm 12) \\
794( \pm 33)-794( \pm 22)-783( \pm 2)-779( \pm 4)\end{array}$ & $\begin{array}{l}501-549( \pm 6)-485( \pm 13)-519( \pm 10) \\
-591( \pm 55)\end{array}$ & 0.9993 \\
\hline Saleeite $\mathrm{Mg}\left(\mathrm{UO}_{2}\right)_{2}\left(\mathrm{PO}_{4}\right)_{2} \cdot 10 \mathrm{H}_{2} \mathrm{O}$ & $\begin{array}{l}16741 \mathrm{w}( \pm 6)-17547( \pm 3)-18340( \pm 15) \\
-19131( \pm 2)-19895( \pm 17) \\
806( \pm 3)-793( \pm 12)-791( \pm 13)-764( \pm 15)\end{array}$ & $\begin{array}{l}447-463( \pm 10)-470( \pm 38)-495( \pm 3) \\
-490( \pm 32)\end{array}$ & 0.9995 \\
\hline $\begin{array}{l}\text { Phosphuranylite } \\
\mathrm{KCa}\left(\mathrm{H}_{3} \mathrm{O}\right)_{3}\left(\mathrm{UO}_{2}\right)_{7}\left(\mathrm{PO}_{4}\right)_{4} \mathrm{O}_{4} \cdot 8 \mathrm{H}_{2} \mathrm{O}\end{array}$ & $\begin{array}{l}\text { Unresolved, centered at } \sim 18835 \\
\text { Unresolved }\end{array}$ & $\mathrm{N} / \mathrm{A}$ & N/A \\
\hline
\end{tabular}

each intense vibronic emission peak displayed by the colored curves. The same behavior is found in unanocircite, not shown here.

The unequivocal discrimination of minerals which have very close emission spectra like saleeite and metatorbernite can be done by examining their decays which are not extending over the same temporal scale. This fact is exemplified in Fig. 5a and b. In general, simple observation of fluorescence maps (Fig. 2) obtained for different sweep ranges provides qualitative signatures of each mineral studied.

For ulrichite, there is no visible effect of refractive index variation $v s$. wavelength despite rapid nanosecond sweep time. The PL kinetics kickoff at time $t_{0}$ does not vary substantially with wavelength as seen by the onsets of PL front in Fig. $5 \mathrm{c}$ after beginning of sweeps. Lifetimes $\tau_{2}$ are found to be about $624 \mathrm{ps}$ for the full spectrum, and $1.1 \mathrm{~ns}$ for the decays at the most intense PL emissions $520 \mathrm{~nm}$ and $541 \mathrm{~nm}$.

Spectral snapshots (thin horizontal yellow ROIs like in Fig. 2f) were extracted from the images at fixed time delays after beginning of streak camera sweep. The temporal evolution of the spectra (not shown) does not display significant changes in the peak positions except for absolute intensities. The PL spectrum of saleeite is slightly red shifted at long time ( $1 \mathrm{~nm}$ to $3 \mathrm{~nm}$ ). In metatorbernite and uranocircite it is not possible to discern a shift of the vibronic lines. As exemplified in Fig. 6, the overall spectra of ulrichite and phosphuranylite narrow as time evolves, and vibronic features are hidden in the noise resulting from the weaker PL signal at longer times.

From previous studies, it is ascertained that free uranyl ions in solutions give lifetimes between $1 \mu \mathrm{s}$ and $5 \mu \mathrm{s}{ }^{44}$ Two compounds in the present study (phosphuranylite and ulrichite) exhibit very short lifetimes (in the range of nanoseconds) in comparison to other minerals of the studied series that luminesce between $5 \mu$ s and $150 \mu$ s (Fig. 4). In phosphuranylite, short decay times can originate from $\mathrm{H}_{3} \mathrm{O}^{+}$groups present in the phase, together with $\mathrm{OH}^{-}$hydroxyls which could quench the luminescence in the solid state. While water molecules can affect the lifetimes of uranyl luminescence, the relationship is not straightforward. The mineral structures are complex, with several types of water sometimes being present. These include lattice water that is not directly bonded to the central uranyl ion, directly bonded water, hydrogen bonded water, and water that is more associated with a second metal ion. Additionally, in

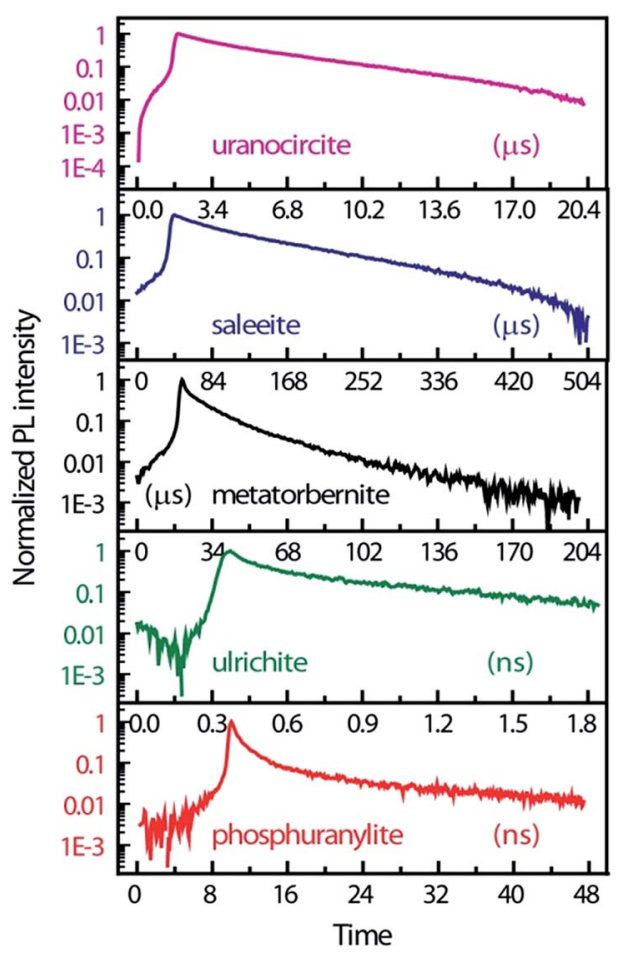

Fig. $4 \mathrm{PL}$ kinetics and temporal profiles observed in the different minerals, integrated over the whole spectral ranges of Fig. 3 and displayed in an intensity log scale normalized to 1. Zero-time delay corresponds to the beginning of the streak camera sweep. 
Table 2 RT luminescence decay lifetimes ( $\tau_{1}, \tau_{2}$ - exponential values, $\tau_{\mathrm{r}}$ and $\tau_{\mathrm{nr}}$ - radiative and non-radiative values) and quantum yield ranges (QY) estimated for the studied minerals by taking $1.1 \times 10^{3}<k_{\mathrm{r}}<2.2 \times 10^{3} \mathrm{~s}^{-1 a, b}$

\begin{tabular}{|c|c|c|c|c|c|c|}
\hline Minerals & $\tau_{1}(\mu \mathrm{s})$ & $\tau_{2}(\mu \mathrm{s})$ & QY range & $\tau_{\mathrm{r}}(\mu \mathrm{s})$ range & $\tau_{\mathrm{nr}}(\mu \mathrm{s})$ range & $R^{2}$ \\
\hline Saleeite & $31.9 \pm 1.4$ & $152.7 \pm 3$ & $0.17-0.34$ & $450-900$ & $184-232$ & 0.9935 \\
\hline Metatorbernite & $10.1 \pm 0.18$ & $31.6 \pm 0.88$ & $0.035-0.07$ & $451-952$ & $33-34$ & 0.9994 \\
\hline $\begin{array}{l}\text { Ulrichite: from } \\
\text { peak at } 19290 \mathrm{~cm}^{-1}\end{array}$ & $(6.5 \pm 0.004) \times 10^{-5}$ & $(1.11 \pm 0.04) \times 10^{-3}$ & $1.2 \times 10^{-6}$ to $2.4 \times 10^{-6}$ & $458-916$ & $\sim 1.1 \times 10^{-3}$ & $\begin{array}{l}0.9218 \text { low signal } \\
\text { to noise ratio }\end{array}$ \\
\hline Phosphuranylite & $(1 \pm 0.1) \times 10^{-3}$ & $(9.1 \pm 0.2) \times 10^{-3}$ & $1 \times 10^{-5}$ to $2 \times 10^{-5}$ & $454-908$ & $\sim 9.1 \times 10^{-3}$ & 0.9900 \\
\hline
\end{tabular}

${ }^{a} R^{2}$ is the correlation coefficient between temporal profiles and kinetics fits. ${ }^{b}$ Deduced from full images except for ulrichite (see Fig. 5).

some uranyl mineral structures, the second metal ion, such as copper(II), exhibiting a $\mathrm{d}^{9}$ electron configuration, is paramagnetic. Paramagnetic ions like copper(II) have been known to affect the lifetimes or PL intensity, with the effect being previously discussed. In the present study, metatorbernite and ulrichite fall into this category, with intralattice coupling of all the molecules in the structure making the exact uranyl ion lifetimewater content relationship uncertain. ${ }^{45,46}$

For this study, we have found rough relationships between the uranyl PL lifetime and U-O bonds. Note that these trends may be absent for other parent minerals. In Fig. 7a, the PL lifetimes of all five minerals decrease with increasing $\mathrm{U}-\mathrm{O}$ bond lengths averaged over each unit cell. Lopez and Birch noted that in solutions of uranyl nitrate hexahydrate the $\left(\mathrm{UO}_{2}\right)_{2}(\mathrm{OH})_{2}{ }^{2+}$ dimer has a longer lifetime than the monomer. ${ }^{38}$ Since the uranyl center in the monomer can be assumed to be at infinite distance to other uranyl centers in the solution, a general rule may be assumed concerning increasing $\mathrm{U} \cdots \mathrm{U}$ distances and decreasing lifetimes.

Another linear relationship is observed between increasing steady-state vibronic separation $\nu_{1}$ given by the energy difference between $(0,0)$ and $(0,1)$ peak transitions of the minerals ${ }^{17}$ and increasing PL lifetimes plotted on a log scale (Fig. 7b). The dependence between the $\nu_{1}$ Raman frequency (or vibronic spacing) and the $\tau_{2}$ lifetime is related with the fact that both quantities seem to increase when the number of water species inside the mineral is augmented, i.e., that water-poor containing minerals have their luminescence quenched. Geipel et al. ${ }^{29}$ observed, indeed, a decrease of the luminescence lifetime by about one order of magnitude from the water-rich to the waterpoor containing uranium(vi) minerals.

A total quantum yield can be determined with TRPL from the following equation:

$$
\Phi=\frac{k_{\mathrm{r}}+k_{\mathrm{ISC}}+k_{\mathrm{IC}}}{\sum k_{i}}
$$

where $k_{\mathrm{r}}, k_{\mathrm{ISC}}, k_{\mathrm{IC}}$ are the rates of radiative luminescence emission, intersystem crossing and internal conversion, where $\sum k_{i}=k$ with $k_{i}$ denoting the rate constants of all the decay processes from the first excited state of the fluorophore. As a result $\sum k_{i}=k_{\mathrm{nr}}+k_{\mathrm{r}}$ and the luminescence quantum yield $\Phi_{\mathrm{f}}$ is given by

$$
\Phi_{\mathrm{f}}=k_{\mathrm{r}} \tau
$$

where $\tau=k^{-1}$ is derived from the PL decay, and $\Phi_{\mathrm{f}}$ should be $<1$. In this analysis, we have taken $k_{\mathrm{r}}$ at two extreme values $1.1 \times 10^{3}$ $\mathrm{s}^{-1}$ and $2.2 \times 10^{3} \mathrm{~s}^{-1}$ from the range given by Olken et al. ${ }^{21}$ and close to the luminescence decay rates of Chan et al. ${ }^{47}$ in crystalline uranyl salts (see Fig. 1 and 2 of that reference). We therefore provide an estimate of $\Phi_{\mathrm{f}}$ bounded between two values by taking $\tau_{2}$ lifetimes which are comparable with those of available literature..$^{\mathbf{4 0 , 4 8 , 4 9}}$

Phosphuranylite and ulrichite quantum yields are very small due to the short decay times. Indeed, by naked eye observation,
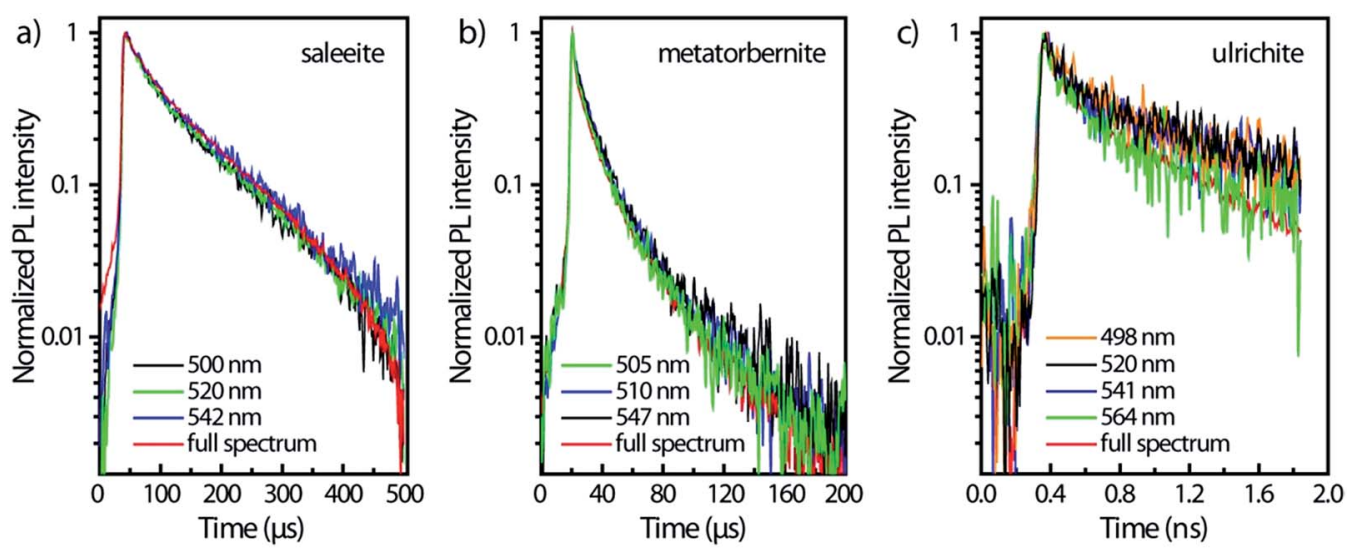

Fig. 5 Temporal profiles of main vibronic peaks in (a) saleeite, (b) metatorbernite, (c) ulrichite limited to 5 nm spectral regions of interest and compared to the decays obtained on the full spectra. Zero-time delay corresponds to the beginning of the streak camera sweep. 

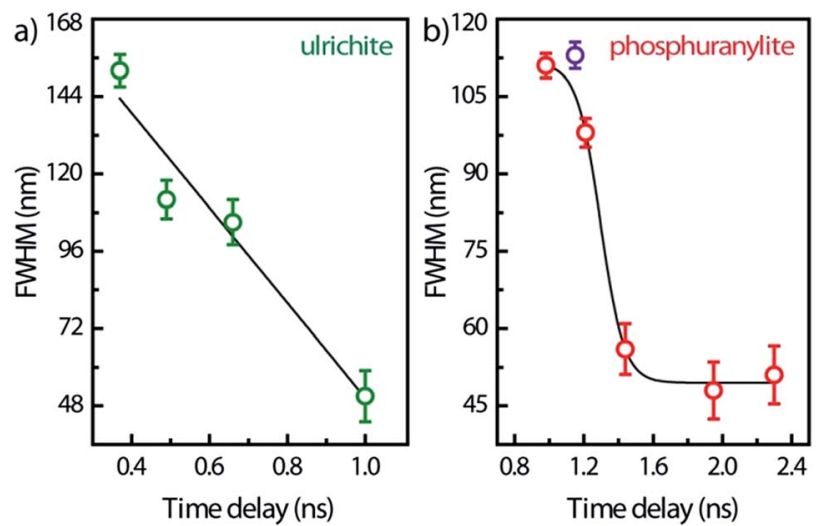

Fig. 6 FWHM temporal variation of the whole PL band in ulrichite and phosphuranylite (see Fig. $2 \mathrm{~d}$ and e) after laser excitation. Solid lines are visual guides; zero-time delay corresponds to the beginning of the streak camera sweep.
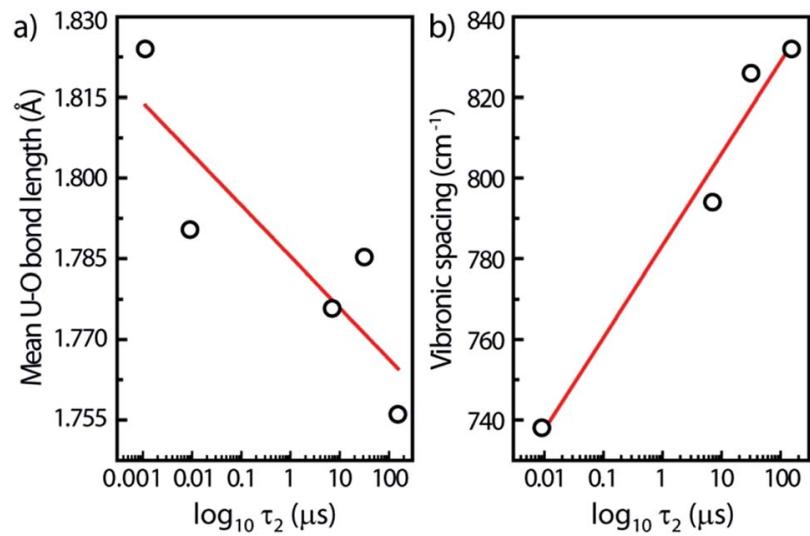

Fig. 7 Mean U-O bond lengths (a) and vibronic spacings (b) in the steady-state $\mathrm{PL}$ taken between the two most intense vibronic peaks $(0,0)$ and $(0,1)$ on the high wavenumber side as function of logarithmic decay lifetimes $\tau_{2}$, for all minerals. Solid lines are linear fits. Errors bars correspond to the symbol size.

it is not possible to discern the luminescence of phosphuranylite and ulrichite under either UV lamp or laser excitation. Qualitatively, saleeite is glowing green intensely at lower laser powers and gives the higher $\Phi_{\mathrm{f}}$, while the glow of metatorbernite and uranocircite is much lesser from photon counts recorded on the CCD detector, in agreement with their $\Phi_{\mathrm{f}}$ estimates.

PL decay analysis can also yield $\tau_{\mathrm{r}}$ radiative or $\tau_{\mathrm{nr}}$ nonradiative lifetimes, since $\Phi_{\mathrm{f}}$ has been determined. Now, it is straightforward to estimate $\tau_{\mathrm{r}}$ and $\tau_{\mathrm{nr}}$

$$
\tau_{\mathrm{r}}=\tau / \Phi_{\mathrm{f}} \text { and } \tau_{\mathrm{nr}}=\tau /\left(1-\Phi_{\mathrm{f}}\right)
$$

which are compiled in Table 2 with $\tau=\tau_{2}$ for the bounded range of $\Phi_{\mathrm{f}}$.

These results show that the photoluminescence technique described here could be applied to remote imaging embarking airborne or seaborne laser luminescence systems for the detection and discrimination of uranium wastes and naturally occurring uranium present inland, in seawater, or on seabeds. Such remote sensing approach could be used on its own or as a complement to gamma ray spectrometry. ${ }^{50-52}$

\section{Conclusions}

Time-resolved photoluminescence imaging with a streak camera provides robust temporal fingerprints permitting to identify or detect low amounts of uranyl phosphates hydrates in the solid state. Luminescence decay lifetimes were used to give a range of luminescence quantum yields and radiative/nonradiative lifetimes in the minerals. The present results have strong implications in environmental analysis by making use for example of embarked devices based on remote laser-excited uranyl sensors for selective detection of uranium in geologic beds or waters.

\section{Acknowledgements}

This work was supported by the U. S. Department of Energy under Contract No. DE-ACO3-76SF00098. We thank V. G. Ivanov for useful discussions and J. Y. Mevellec for crystals microphotographs.

\section{References}

1 E. Rabinowitch and R. L. Belford, in International Series of Monographs on Nuclear Energy, Division XII: Chemistry, Pergamon Press, Oxford, 1964.

2 H. D. Burrows and T. J. Kemp, Chem. Soc. Rev., 1974, 3, 139165.

3 C. K. Jørgensen and R. Reisfeld, Chem. Phys. Lett., 1975, 35, 441-443.

4 D. L. Perry, H. Ruben, D. H. Templeton and A. Zalkin, Inorg. Chem., 1980, 19, 1067-1069.

5 H. G. Brittain and D. L. Perry, J. Phys. Chem., 1980, 84, 26302634.

6 S. J. Formosinho, H. D. Burrows, M. da Graça Miguel, M. E. D. G. Azenha, I. M. Saraiva, A. C. D. N. Ribeiro, I. V. Khudyakov, R. G. Gasanov, M. Bolte and M. Sarakha, Photochem. Photobiol. Sci., 2003, 2, 569-575.

7 R. G. Denning, J. Phys. Chem. A, 2007, 111, 4125-4143.

8 C. K. Jørgensen and R. Reisfeld, in Topics in Inorganic and Physical Chemistry, Springer, Berlin, Heidelberg, 1982, vol. 50, pp. 121-171.

9 G. Meinrath, J. Radioanal. Nucl. Chem., 1997, 224, 119-126.

10 M. E. Azenha and G. Blasse, J. Alloys Compd., 1993, 196, 8185.

11 E. Fritsch, L. Mihut, M. Baibarac, I. Baltog, M. Ostrooumov, S. Lefrant and J. Wery, J. Appl. Phys., 2001, 90, 4777-4782.

12 Z. Wang, J. M. Zachara, P. L. Gassman, C. Liu, O. Qafoku, W. Yantasee and J. G. Catalano, Geochim. Cosmochim. Acta, 2005, 69, 1391-1403.

13 M. Del Nero, C. Galindo, R. Barillon and B. Madé, Environ. Sci. Technol., 2011, 45, 3982-3988. 
14 R. Vochten and K. Van Springel, Mineral. Mag., 1996, 60, 647-651.

15 A. O. Matkovskiy, G. A. Sidorenko and A. N. Tarashchan, Int. Geol. Rev., 1981, 23, 91-95.

16 G. Wang, Y. Su and D. L. Monts, J. Phys. Chem. A, 2008, 112, 10502-10508.

17 E. Faulques, N. Kalashnyk, F. Massuyeau and D. L. Perry, RSC Adv. , 2015, 5, 71219-71227.

18 J. B. M. Novo, F. R. Batista, C. J. da Cunha, L. C. Dias and F. B. T. Pessine, J. Lumin., 2007, 124, 133-139.

19 N. Baumann, T. Arnold, H. Foerstendorf and D. Read, Environ. Sci. Technol., 2008, 42, 8266-8269.

20 G. Othmane, T. Allard, T. Vercouter, G. Morin, M. Fayek and G. Calas, Chem. Geol., 2016, 423, 1-6.

21 M. M. Olken, R. N. Biagioni and A. B. Ellis, Inorg. Chem., 1983, 22, 4128-4134.

22 M. Moriyasu, Y. Yokoyama and S. Ikeda, J. Inorg. Nucl. Chem., 1977, 39, 2211-2214.

23 M. Moriyasu, Y. Yokoyama and S. Ikeda, J. Inorg. Nucl. Chem., 1977, 39, 2199-2203.

24 R. G. Denning, C. N. Ironside, J. R. G. Thorne and D. R. Woodwark, Mol. Phys., 1981, 44, 209-224.

25 L. V. Haley and J. A. Koningstein, J. Phys. Chem. Solids, 1983, 44, 431-433.

26 M. Lopez and D. J. S. Birch, Analyst, 1996, 121, 905-908.

27 V. Brendler, G. Geipel, G. Bernhard and H. Nitsche, Radiochim. Acta, 1996, 74, 75-80.

28 C. Moulin, I. Laszak, V. Moulin and C. Tondre, Appl. Spectrosc., 1998, 52, 528-535.

29 G. Geipel, G. Bernhard, M. Rutsch, V. Brendler and H. Nitsche, Radiochim. Acta, 2000, 8, 757-762.

30 N. Baumann, V. Brendler, T. Arnold, G. Geipel and G. Bernhard, J. Colloid Interface Sci., 2005, 290, 318-324.

31 Z. Wang, J. M. Zachara, C. Liu, P. L. Gassman, A. R. Felmy and S. B. Clark, Radiochim. Acta, 2008, 96, 591-598.

32 S. A. Miller and J. C. Taylor, Z. Kristallogr., 1986, 177, 247253.
33 A. J. Locock and P. C. Burns, Can. Mineral., 2003, 41, 489502.

34 A. O. Matkovskiy, G. A. Sidorenko and A. N. Tarashchan, Int. Geol. Rev., 2010, 23, 91-95.

35 U. Kolitsch and G. Giester, Mineral. Mag., 2001, 65, 717-724.

36 F. Demartin, V. Diella, S. Donzelli, C. M. Gramaccioli and

T. Pilati, Acta Crystallogr., Sect. B: Struct. Sci., 1991, 47, 439-446.

37 A. Kasdan, R. J. L. Chimenti and J. P. deNeufville, Appl. Opt., 1981, 20, 1297-1307.

38 M. Lopez and D. J. S. Birch, Chem. Phys. Lett., 1997, 268, 125132.

39 J. Su, K. Zhang, W. H. E. Schwarz and J. Li, Inorg. Chem., 2011, 50, 2082-2093.

40 C. K. Jørgensen, J. Electrochem. Soc., 1983, 130, 681-684.

41 R. L. Frost, J. Čejka and G. Ayoko, J. Raman Spectrosc., 2008, 39, 495-502.

42 R. J. P. Driscoll, D. Wolverson, J. M. Mitchels, J. M. Skelton, S. C. Parker, M. Molinari, I. Khan, D. Geeson and G. C. Allen, RSC Adv., 2014, 4, 59137-59149.

43 Database of Raman spectroscopy, X-ray diffraction and chemistry of minerals, http://rruff.info/.

44 V. Eliet, G. Bidoglio, N. Omenetto, L. Parma and I. Grenthe, J. Chem. Soc., Faraday Trans., 1995, 91, 2275-2285.

45 M. Frisch and C. L. Cahill, Dalton Trans., 2005, 1518-1523.

46 A.-G. D. Nelson and T. E. Albrecht-Schmitt, C. R. Chim., 2010, 13, 755-757.

47 W. K. Chan, K. H. Chun, T. W. Lai and A. F. Leung, Can. J. Phys., 1979, 57, 2045-2049.

48 C. D. Flint and P. A. Tanner, J. Chem. Soc., Faraday Trans., 1984, 80, 219-226.

49 V. Sytko and M. Pershina, Proc. SPIE, 1995, 2531, 272-280.

50 J. P. DeNeufville, A. Kasdan and R. J. L. Chimenti, Appl. Opt., 1981, 20, 1279-1296.

51 A. T. McCay, T. L. Harley, P. L. Younger, D. C. W. Sanderson and A. J. Cresswell, Energies, 2014, 7, 4757-4780.

52 M. S. Ramayya, A. K. Chaturvedi, I. Patra, D. Srinivas and P. Yadagiri Reddy, J. Geol. Soc. India, 2014, 84, 311-318. 